\title{
Late ANC in the Rural Areas: Case of Saint Elizabeth General Hospital Shisong and its Health Institutions, Cameroon
}

\begin{abstract}
Mbinkar Adeline Venyuy ${ }^{1,2}$, Samuel Nambile Cumber ${ }^{3,4,5}$, Claude Ngwayu Nkfusai ${ }^{2,6 *}$, Solange Ngo Bama ${ }^{7}$, Esther Teng Mbong ${ }^{8}$, Terrence Beteck Epie ${ }^{2,9}$, Yunga Patience Ijang ${ }^{1}$, Fala Bede ${ }^{3}$ and Tebeu Pierre Marie ${ }^{1}$
\end{abstract}

${ }^{1}$ Department of Public Health, Catholic University of Central Africa, Cameroon

${ }^{2}$ Cameroon Baptist Convention Health Services (CBCHS), Cameroon

${ }^{3}$ Department of Public Health and Community Medicine, University of Gothenburg, Sweden

${ }^{4}$ Faculty of Health Sciences, University of Pretoria Private Bag X323, South Africa

${ }^{5}$ Faculty of Health Sciences, University of the Free State, South Africa

${ }^{6}$ Department of Microbiology and Parasitology, University of Buea, Cameroon

${ }^{7}$ Ministry of Public Health, Cameroon

${ }^{8}$ Pan African University of Life and Earth Science Institute, University of Ibadan- Nigeria

${ }^{9}$ Centre for Tropical Medicine and Global Health, Nuffield Department of Medicine, University of Oxford, United Kingdom

Submission: July 23, 2019, Published: August 26, 2019

*Corresponding author: Claude Ngwayu Nkfusai, Cameroon Baptist Convention Health Services (CBCHS), Cameroon

\section{Abstract}

Background: In Cameroon, $66 \%$ of women begin their first ANC during the second trimester of pregnancy. The WHO recommends that normally the overall women should start the ANC before the age 14 weeks but not later than 16weeks during the first trimester. The general objective was to analyse the determinants of late ANC among pregnant women in the SEGHS and its health institutions.

Methods: This was a cross sectional analytic study carried out from 24th October to 24th November, 2016. A total of 602 pregnant women in the ANC units were recruited. The dependent variable was age of ANC initiation while the independent variables were individual, community and institutional factors. Data was analysed using Epi info 7. Odd ratio (OR) with 95\% confidence interval were used to appreciate the influence of different variables on risk of late ANC initiation ( $>14$ weeks of pregnancy). The level of significance was set out at ( $\mathrm{p}:<0.05$ ).

Results: Of the 602 pregnant women included in this study, 75\% initiated ANC after 14weeks of pregnancy. The individual determinants that favoured the late ANC among these women included; age $>27$ years (OR:2.38[1.61-3.51], $\mathrm{p}=0.0001$ ), level of education below secondary (OR= $1.74[1.19-2.55] \mathrm{p}=0.0042)$, advanced parity $(>2$ children) (OR=5.04[3.04-8.36] $\mathrm{p}=0.0001)$. The health system determinants which favoured late ANC were; high cost of care (OR=1.63[1.13-2.37], $\mathrm{p}=0.0095)$ and far distance $(>5 \mathrm{~km})(\mathrm{OR}=1.55[1.07-2.25], \mathrm{p}=0.0209)$.

Conclusion: Late ANC attendance was linked to factors that ranged from individual, community and health institutions as earlier explained. Individual determinants (age: $>27$ years, level of education below secondary, advanced parity ( $>2$ children) and health care system determinants (expensive cost of care and far distance) favoured late ANC among pregnant women in the SEGHS and its health institutions.

Keywords: Determinants; Late ANC; Pregnant women; Health institutions

Abbreviations: HIV: Human Immune Virus; AIDS: Acquire Immune Deficiency Syndrome; WHO: World Health Organization; ANC: Antenatal Care; UNFPA: United Nations Population Fund; UNICEF: United Nations International Children and Emergency Fund; DHS/MIC: Demographic Health Survey/ Mix; USA: United States America; SCLT: Social Cognitive Learning Theory; TB: Tuberculosis; OR: Odd Ratio; AOR: Adjusted odds ratio; CI : Confidence Intervalle; PNC : Post Natal; USB: Universal Serial Bus; APPPB: African Progress Panel Policy brief; SEGHS: Saint Elizabeth General Hospital Shisong; UK: United Kingdom; CPN: Consultation Prenatal

\section{Introduction}

Antenatal care (ANC), along with family planning, birth preparedness, skilled delivery care, and emergency obstetric care,

is a key element of the package of services aimed at improving maternal and new born health. To achieve every Woman Every 
Child vision and the Global Strategy for Women's Children's and Adolescents' Health, we need innovative approaches to antenatal care and evidence-based approaches to antenatal care [1]. ANC has a vital role in the reduction of maternal mortality with its components being; health promotion, disease prevention, early detection and treatment of complications and diseases, and birth and emergency preparedness. ANC from skilled health professional is important to monitor the pregnancy and reduce morbidity and mortality risk for the mother and child during pregnancy and delivery. In Cameroon, 85\% of pregnant women attended at least one ANC visit in 2011. However, only 34\% began ANC before the fourth month [2].

Good care during pregnancy is important for the health of the mother and the development of the unborn baby. Pregnancy is a crucial time to promote healthy behaviors and parenting skills. Good ANC links the woman and her family with the formal health system, increases the chance of using a skilled attendant at birth and contributes to good health through the life cycle. Inadequate care during this time breaks a critical link in the continuum of care, and affects both women and babies [3].

The benefits of ANC in the reduction of maternal morbidity and mortality cannot be overemphasized. Studies have been done in Cameroon to assess ANC services utilization in various settings. However, limited studies have been done to assess the determinants of late ANC especially in rural areas. Therefore, the necessity of this study to whose findings and suggestions can be useful in the reduction of maternal morbidity and mortality.

\section{Methods}

\section{Study design}

The study was a quantitative research. Cross sectional analytic study was done using clinical method.

\section{Duration of study}

The period of study involved then period during which data was collected, it ran for a month $\left(24^{\text {th }}\right.$ October to $24^{\text {th }}$ November, 2016).

\section{Study population}

The target population was all pregnant women attending ANC in the Saint Elizabeth Catholic Hospital and its health institutions.

\section{Inclusion criteria}
a) All women who were pregnant and
b) who have started antenatal consultation and
c) Who accepted to participate in our study?

\section{Exclusion criteria}

a) All pregnant women who were seriously sick

b) All pregnant women who started their ANC in another health institution different from these two.

\section{Sampling methods}

The sample type is non-probable of convenience.

Sample size in a cross sectional analytic study

To calculate our sample size, the Schlesseman formula was used. It stipulates;

- $\quad$ Po $=$ Proportion of exposure in the witness group $92 \%$

- $\quad \mathrm{P} 1=$ Proportion of exposure in the case group $76 \%$

- $\alpha=0.05 \rightarrow \mathrm{Z} \alpha=1.65$

- $\quad \beta=0.1 \rightarrow \mathrm{Z} \beta=1.28$

- $\mathrm{p}=84 \%$

- $\quad \mathrm{N}=2 \mathrm{P}(1-\mathrm{P})(\mathrm{Z} \alpha+\mathrm{Z} \beta)^{2}$

- $\quad(\mathrm{Po}-\mathrm{P} 1)^{2}$

The determinant of women estimated to have attended ANC early during first birth $92 \%$ and $76 \%$ after several deliveries according to 2011 CDHS.

\section{Variables}

\section{Dependent variable}

A dependent variable is said to be "the effect of the manipulation of the independent variable" [4]. This variable is the operational variable which is used to measure the modification to show the attitude and behaviour of women in regards to early initiation of ANC. The dependent variable is late prenatal consultation.

\section{Independent variables}

Nkoum, 2005 referred to an independent variable as a "mobile element of the hypothesis". This variable is the cause that influences the dependent variable.

\section{Data collection tool/technique}

A questionnaire which was sub-divided into four parts was used for data collection. It consisted:

a) Individuals' factors have an influence on late ANC attendance among women in the ANC unit of the Saint Elizabeth general hospital and its health institutions.

b) Community related determinants influence late ANC attendance among women of the ANC unit in the Saint Elizabeth general hospital and its health institutions.

c) Health system determinants are related to late ANC attendance among women in the ANC unit in the Saint Elizabeth general hospital and its health institutions.

In order to meet the objectives of this study, data was collected in accordance with each determinant. Data collection technique matters a lot in a scientific research work, in this regard; a semidirective technique was used to gather information. 


\section{Pre-test and validation of data collection tools}

The researcher used this procedure to assure the feasibility and validity of the data colleting tool. It is a trial process to determine if the data collecting tool can permit to collect reliable data. This tool is elaborated by the student herself and submitted to the research director for correction and validation.

\section{Data storage}

A data spread sheet was created into which collected data was introduced and analyse through the Epi-info 7. Software. Results were presented in a word software before being presented in wards.

\section{Statistical analysis}

Data was introduced in to Epi-info 7 software. Data analysis was done using the same software and results treated in the ward sheet form and presented inside ward. Through cross tabulation of variables, the data was captured and assessment for frequency tabulation data was analysed.

\section{Statistic calculations}

Certain variables are being recorded and their frequencies calculated. The odd report was used (Odd Ratio: OR) with the confidence interval set at $95 \%$ of different variable which permit to measure the danger of late prenatal consultation if and a difference is considered significant if, $\mathrm{P}<0,05$. In the adjusted analysis, we searched for all the confusion factors of each significant variable in brut analysis and the adjusted on every one of the variables. We are going to calculate the confusion factor. Analysed results will be presented in form of figure and tables. The Chi Square test and logistic regression permitted us to measure the association between variable.

\section{Ethical consideration}

In order to respect ethical norms, this study was preceded as follow;

a) We obtained an authorization from the Director of School of Health Sciences Messa Campus.

b) Another one from the Shisong hospital to meet with Matron to obtain her permission to access to the health centre.

c) Obtain a research authorization from the Director of the saint Elizabeth catholic Hospital were our research will take place.

d) Seek the opinion of participants before interview assuring them of the animosity of their identity.

e) An information notice was submitted to them

\section{Result}

\section{Distribution of pregnant women according to the age of initiation of ANC}

The results were presented following the specific objectives of the work including bivariate and multivariate analysis using Epi-info 7 in order to permit the understanding of this work. The results were interpreted at $95 \%$ confidence interval with p: 0.05 (Figure 1).

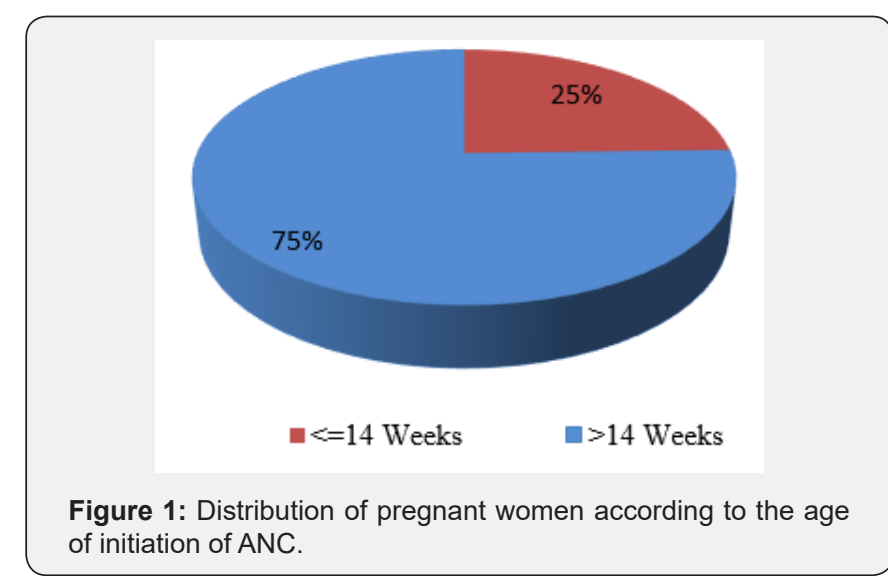

\section{Individual determinants of late ANC among women in the SEGHS and its health institutions}

As an objective of this study, the individual factors such as socio-demographic and reproductive health characteristics of the respondents were analysed. This was to find out the likelihood to which they can influence the gestational age at which ANC is initiated. The table below gives an appraisal of this analysis (Table 1).

Table 1: Individual characteristics of the respondents according to ANC initiation.

\begin{tabular}{|c|c|c|c|c|}
\hline \multirow[t]{4}{*}{ Characteristics } & \multicolumn{2}{|c|}{ Age of Initiation of ANC } & \multirow{4}{*}{$\begin{array}{c}\text { Total } \\
602 \\
\text { N (\%) }\end{array}$} & \multirow{4}{*}{ P-Value } \\
\hline & $>14$ weeks & $\leq 14$ weeks & & \\
\hline & $\mathrm{N}=454$ & $\mathrm{~N}=148$ & & \\
\hline & N (\%) & N (\%) & & \\
\hline \multicolumn{5}{|c|}{ Age } \\
\hline $30-44$ & $242(53.30)$ & $48(32.43)$ & $290(48.17)$ & \\
\hline $15-29$ & $212(46.70)$ & $100(67.57)$ & $312(51.83)$ & $0.001^{*}$ \\
\hline \multicolumn{5}{|c|}{ Level of Education } \\
\hline$\leq$ Primary & $228(50.11)$ & $53(36.05)$ & $281(46.68)$ & \\
\hline
\end{tabular}


Journal of Gynecology and Women's Health

\begin{tabular}{|c|c|c|c|c|}
\hline$\geq$ Secondary & $227(49.89)$ & $94(63.95)$ & $321(53.32)$ & $0.002^{*}$ \\
\hline \multicolumn{5}{|c|}{ Marital Status } \\
\hline Not married & $346(87.37)$ & $98(47.57)$ & $444(73.75)$ & \\
\hline Married & $50(12.63)$ & $108(52.43)$ & $158(26.25)$ & $0.016^{*}$ \\
\hline \multicolumn{5}{|c|}{ Religion } \\
\hline Christians & $127(85.81)$ & $353(77.75)$ & $480(79.73)$ & \\
\hline Muslims & $21(14.19)$ & $101(22.25)$ & $122(20.27)$ & $0.034^{*}$ \\
\hline \multicolumn{5}{|c|}{ Gravidity } \\
\hline $2-9$ & $339(74.67)$ & $82(55.41)$ & $421(69.93)$ & \\
\hline 1 & $115(25.33)$ & $66(44.59)$ & 181(30.07) & $0.001 *$ \\
\hline \multicolumn{5}{|c|}{ Parity } \\
\hline $4-8$ & $254(55.95)$ & $128(86.49)$ & $382(36.54)$ & \\
\hline $0-3$ & $200(44.05)$ & $20(13.51)$ & $220(63.46)$ & $0.001 *$ \\
\hline
\end{tabular}

*: significant variables

\section{Community determinants of late ANC among pregnant women in the SEGHS and its health institution}

Table 2: Community characteristics with respect to ANC initiation.

\begin{tabular}{|c|c|c|c|c|}
\hline \multirow[t]{2}{*}{ Characteristics } & \multicolumn{2}{|c|}{ Age of Initiation of ANC } & \multirow[b]{2}{*}{$\begin{array}{c}\text { Total } \\
602 \\
\text { N (\%) }\end{array}$} & \multirow[t]{2}{*}{ p-value } \\
\hline & $\begin{array}{c}>14 \text { weeks } \\
\mathrm{N}=148 \\
\mathrm{~N}(\%)\end{array}$ & $\begin{array}{c}\leq 14 \text { weeks } \\
\mathrm{N}=454 \\
\mathrm{~N}(\%)\end{array}$ & & \\
\hline \multicolumn{5}{|c|}{ Decision-Maker } \\
\hline Couple & $383(84.36)$ & $117(32.40)$ & $500(83.06)$ & 1.135 \\
\hline Others & $71(15.64)$ & $31(20.95)$ & $102(16.94)$ & \\
\hline \multicolumn{5}{|c|}{ Financial Supporter } \\
\hline Others & 85 (25.99) & $28(28.00)$ & $113(26.46)$ & 0.690 \\
\hline Parent of child & $242(74.01)$ & $72(72.00)$ & $314(73.54)$ & \\
\hline \multicolumn{5}{|c|}{ Husband's Profession } \\
\hline Non C S & $53(15.36)$ & $11(11.22)$ & $64(14.45)$ & 0.304 \\
\hline CS & $292(84.64)$ & $87(88.78)$ & $379(85.55)$ & \\
\hline \multicolumn{5}{|c|}{ Transport Fare } \\
\hline $0-500$ & $314(69.16)$ & $101(64.24)$ & $415(68.94)$ & 0.834 \\
\hline 600 and above & $140(30.84)$ & $47(31.76)$ & $187(31.06)$ & \\
\hline \multicolumn{5}{|c|}{ Source of Income } \\
\hline No & 327 (72.03) & $48(32.43)$ & $375(62.29)$ & $0.001^{*}$ \\
\hline Yes & $127(27.97)$ & $100(67.57)$ & $227(37.71)$ & \\
\hline
\end{tabular}

*others: other family members

${ }^{*} \mathrm{CS}$ : civil servants

It is known that the environment of an individual influences certain decisions in life. This could be applied also to the choice of when to begin ANC among the women of this community. It is important to know those community factors that can influence the time of ANC initiation (Table 2).

\section{Discussion}

Women or respondents who reported that the cost of ANC was unaffordable were more likely to initiate ANC late compared to their counterparts (OR: 1.6347, p: 0.0095). This could be as a reason of good management when they become aware of their pregnancy or better still it could be for their pregnancies are wanted pregnancies. A study in Nigeria by [5] reported that most women initiate ANC late, related to lack of finances for the use of ANC services. The financial barrier as an influential factor to late ANC is seen in studies of [6] in Tanzania and [7] in Muea, Cameroon. To these women and even women who had not attended ANC before when interviewed said this barrier of cost 
fee would not be difficult to overcome. The behaviour of pregnant women with respect to late ANC could be linked to the lack of finances where the first visit often demands more. These women express that it is not always easy to afford the amount required given the standard of life in rural areas. With the unavailability of finances, these women find it difficult to attend the ANC early as they may not be able to afford the services. When there is this financial barrier the ease to care is obstructed thus delay in ANC attendance.

In this study, women who felt that the distance to the health centre has an influence on the initiation of ANC were more likely to start their ANC before the $14^{\text {th }}$ week of pregnancy than those who reported that distance had no influence at all (OR: 1.51, p: 0.0209). A study carried out in Rwanda by [8] feeling that distance to health facility is a problem that had an influence of decision taking on ANC initiation (OR: 1.20, 95\% CI: 1.04-1.38). This brings about the need for PEER educators to be used to follow up women in their various health sectors during campaign programs.

This study reported that for some women the fluctuating nature of the cost or fee to pay during ANC was a problem. Those who identified that the cost of ANC when stable though not affordable were more likely to initiate it earlier than those who said it was unstable and unaffordable (OR: 3.2098, p: 0.0143 ). this meant that they were already prepared to pay the cost even if unaffordable, but when it varies per visits with little understanding form the women it kind of discourage some of them from going for ANC. This study reported slightly above half of the respondents was satisfied with the ANC. This was lower than the $81.1 \%$ in Ibadan, Nigeria by [9]. The satisfaction of ANC influences the initiation of ANC. Women reported that they could not go to the hospital for ANC initiation if they did not have money. This emphasis on the importance of meeting individual needs through adequate and sufficient personnel. Due to the fact that the personnel is limited, work load become a barrier to meeting the needs of these women reason why the hospital has to employ more persons in this sector.

Women who reported that other women did not see quality of care as being satisfying had a 4.75 risk of initiate ANC late than their counterparts. The results showed 297/602 (49.34\%) of women were not satisfied on the care they received. This was related among others to long waiting hours (58.44\%), numerous visits $(21.81 \%)$, and attitude of workers $(15.44 \%)$. This actually impacted on their attending and initiating ANC on time. The fact that more of them perceived the care as being satisfactory could be because of their low expectations of health care services. For as reported by [10] in South Sudan, that these women either started their consultation in the second, third or fourth trimester or never attended at all. There is the need for good health education with modern tools to be put in place to help counsel the negative reasoning women bring from quarters that hinder them to apply what they are told during health education. This is to help reduce maternal and infant mortality rate as a whole.

\section{Conclusion}

Antenatal consultation is a major intervention adopted in Cameroon by the Ministry of Public Health in the reduction of its maternal mortality ratio. Women are advised to seek medical care as soon as they realise they are pregnant, often before the fourth month. However, Cameroon still experiences a high proportion of late ANC attendance among pregnant women. This study was on the determinants of late antenatal consultation among pregnant women in the SEGHS and its health institutions. It had as objectives to identify the individual factors which among that proved significant were, the age of woman, level of education, marital status, religion and gravidity. As to community factors, permanent source of income revealed itself as the centre concerned and health institutional factors that will influence late ANC were cost affordability, cost price of ANC, opinion of others on when to initiate, influence of distance and satisfaction derived from ANC.

Late ANC attendance was linked to factors that ranged from individual, community and health institutions as earlier explained. This study provides necessary information to contribute to the reduction of late attendance of ANC thus providing chances for oriented interventions towards the detection of maternal problems which could be fatal to both her health and that of her baby to be.

\section{What is Already Know About the Topic}

a) Prevalence and risk factors for non-use of antenatal care visits

b) Determinants of antenatal care attendance among pregnant women living in endemic malaria settings

c) Factors contributing to late antenatal booking among pregnant women in Ibore Primary Health Center in Esan Central Local Government Area

\section{What this Study Adds}

a) This study was on the determinants of late antenatal consultation among pregnant women in the SEGHS and its health institutions

b) As to community factors, permanent source of income revealed itself as the centre concerned and health institutional factors that will influence late ANC were cost affordability, cost price of ANC, opinion of others on when to initiate, influence of distance and satisfaction derived from ANC

c) Late ANC attendance was linked to factors that ranged from individual, community and health institutions as earlier explained. 


\section{Authors Contribution}

MAV, SNC, CNN, SNB, ESM, FB and TPM designed the study and were involved in all aspects of the study. MAV, FB, SNC and NCN contributed to scientifically reviewing the manuscript for intellectual inputs and review. All authors reviewed the final manuscript and agreed for submission.

\section{Acknowledgement}

We are grateful to all who participated in this research.

\section{References}

1. WHO (2010) IMPAC Integrated Management of Pregnancy and Childbirth WHO Recommended Interventions for Improving Maternal and New born Health. World Health Organization, Geneva, Switzerland.

2. Ministère de la Santé Publique (2011) Plan national d'élimination de la transmission mère enfant du VIH à l'horizon 2015 au Cameroun. Comité National de Lutte contre le Sida, Yaoundé, Cameroon.

3. Ministère de la Santé Publique (2014) Soins obstétricaux et néonataux essentiels et d'urgence. Minsanté, Yaoundé, Cameroon.

4. Nkoum BA (2010) Initiation à la recherché: une nécessité professionnelle. Yaoundé-Cameroon: Deuxième édition Presses de l'UCAC, p. 179.
5. Adeniy FF, Idemmdia ES (2015) Barriers to antenatal care in Nigeria evidences from non-users and implications for maternal health programming. BMC Pregnancy and Childbirth 15: 95.

6. Gross K, Alba S, Glass TR, Schellenberg JA, Obrist B, et al. (2012) Timing of antenatal care for adolescent and adult pregnant women in southeastern Tanzania. BMC Pregnancy and Childbirth 12: 16.

7. Ekane GEH, Egbe T, Nnomzo'o JL, Nzang NMM, Mafany N, et al. (2014) Assessment of the Content and Utilization of Antenatal Care Services in a Rural Community in Cameroon: A Cross-Sectional Study. Women Health Open Journal 1(2): 31-39.

8. Manzi A, Francisca F, Mujawase BL, Sayinzoga F, Dana RT, et al. (2010) Assessing predictors of delayed antenatal care visits in Rwanda: a secondary analysis of Rwanda demographic and health survey 2010. BMC Pregnancy Childbirth 14: 290.

9. Nwaeze IL, Enabor O0, Oluwasola TAO, Aimakhu CO (2013) Perception and satisfaction with quality of antenatal care services among pregnant women at the University College Hospital, Ibadan, Nigeria. Ann Ib Postgrad Med 11(1): 22-28.

10. Mugo NS, Dibley MJ, Agho KE (2015) Prevalence and risk factors for non-use of antenatal care visits: analysis of the 2010 South Sudan household survey. BMC Pregnancy and Childbirth 15: 68.

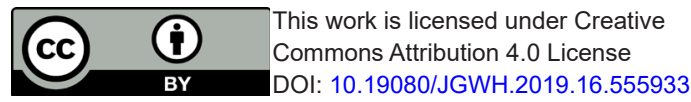

\section{Your next submission with Juniper Publishers will reach you the below assets}

- Quality Editorial service

- Swift Peer Review

- Reprints availability

- E-prints Service

- Manuscript Podcast for convenient understanding

- Global attainment for your research

- Manuscript accessibility in different formats

( Pdf, E-pub, Full Tsext, Audio)

- Unceasing customer service

Track the below URL for one-step submission https://juniperpublishers.com/online-submission.php 